\title{
A INTERCULTURALIDADE NA FORMAÇÃO DOS PROFISSIONAIS DE ENFERMAGEM
}

\author{
Rosane Teresinha Fontana ${ }^{1}$
}

\begin{abstract}
RESUMO
Trata-se de uma proposta de reflexão sobre a interculturalidade e a formação em Enfermagem, que utilizou a revisão narrativa como método. A interculturalidade vem se configurando como uma nova perspectiva epistemológica e como um objeto de estudo interdisciplinar e transversal. $O$ estudo se justifica visto que tematizar sobre sua complexidade na formação em Enfermagem pode agregar valor ao cuidado. Em todas as áreas do conhecimento, a diversidade cultural só pode ser promovida ao reconhecer, como princípio fundador, o diálogo e o respeito entre as civilizações e as culturas. Além disso, constitui força motriz do desenvolvimento, indispensável para atenuar a pobreza e promover tanto a igualdade quanto a equidade na assistência à saúde.
\end{abstract}

Palavras-chave: Interculturalidade. Ensino. Enfermagem.

\section{INTERCULTURALITY IN THE TRAINING OF NURSING PROFESSIONALS}

\section{ABSTRACT}

This is a proposal for reflection on interculturality and nursing education, which used narrative revision as a method. Interculturality is becoming a new epistemological perspective and as an object of interdisciplinary and transversal study. The study is justified since the thematizing about its complexity in nursing training can add value to care. In all areas of knowledge, cultural diversity can only be promoted by recognizing, as a founding principle, dialogue and respect between civilizations and cultures. It is also a driving force for development, which is essential for alleviating poverty and promoting both equity and equity in health care.

Keywords: Interculturality. Teaching. Nursing.

RECEBIDO EM: 10/1/2019

ACEITO EM: 10/2/2019 
De acordo com Hepburn (2005, p. 254), o próprio conceito de intercultura já apresenta a complexidade que é tratar deste assunto. Questões de etnia, raça, cor, gênero, entre outros, são temas que antes de tudo precisam mudar o modo de ver o mundo, o que exige a suspensão de preconceitos e a compreensão das diferenças e identidades culturais de cada povo. Isso se justifica pelo fato de o mundo "poder ser comparado a um mosaico ou a uma tapeçaria composta de múltiplas contribuições culturais, em que cada uma contribui para o significado e a beleza do conjunto".

O conceito de formação intercultural ainda está em construção. Um contato superficial com o tema pode sugerir que a intercultura busca harmonizar a convivência entre diferentes culturas, excluindo ou minimizando conflitos, na medida em que uma cultura tolere a outra. Mas não se pretende desenvolver tolerância. Tolerar significa suportar, aguentar, e essa não é uma relação de igualdade, mas de superioridade de uma cultura sobre a outra. $\mathrm{O}$ que se pretende é desenvolver relacionamentos cooperativos entre as diferentes culturas, em que sejam mantidas - e respeitadas - as identidades culturais. A intercultura não busca a hegemonia, mas o reconhecimento da diversidade. Os conflitos permanecem inclusive em nome da democracia, mas devem existir em uma condição de igualdade, onde as diferenças não se reflitam em preconceitos e discriminações (VIEIRA, 2001, p. 118).

A interculturalidade vem se conformando como uma perspectiva epistemológica, de estudo interdisciplinar e transversal. Propõe-se a abordar a complexidade "(para além da pluralidade ou da diversidade) e a ambivalência ou o hibridismo (para além da reciprocidade ou da evolução linear) dos processos de elaboração de significados nas relações intergrupais e intersubjetivas, constituídas de campos identitários em termos de etnias, de gerações, de gênero, de ação social" (FLEURI, 2003, p. 17).

Em um primeiro momento falava-se em multiculturalidade. Abordada a partir das políticas sociais e educativas, tinha (e ainda tem) como escopo adaptar os outros aos costumes, valores e organização da sociedade receptora, considerada superior. Essa perspectiva estava associada a fenômenos migratórios e se alicerçava na ideia de que diferentes culturas não podiam conviver em um mesmo contexto social. Assim, o grupo majoritário absorvia o minoritário. Neste movimento o último perde sua identidade, sua língua, seus hábitos e até mesmo sua religião (SANCHEZ, 2001). É neste contexto, que emerge a interculturalidade, como um processo de dupla via, num movimento em que a cultura inserida e a local oferecem elementos para a dinamicidade cultural (ZWIEREWICZ; VALLEJO, 2006).

A perspectiva intercultural é dirigida à edificação de uma sociedade democrática, plural, humana, que articule políticas de igualdade com políticas de identidade. Envolve o reconhecimento do outro, o diálogo entre os diferentes grupos sociais e culturais. A adoção do olhar intercultural favorece a superação das relações de dominação (CANDAU, 2008, p. 52). Para Wash (2001), a interculturalidade é "[...] um processo dinâmico e permanente de relação, comunicação e aprendizagem entre culturas em condições de respeito, legitimidade mútua, simetria e igualdade", construído entre diferentes pessoas, saberes e práticas culturais, que busca um novo sentido para essas diferenças. Envolve uma tarefa social e política, interpelada e traduzida pelo reconhecimento e confronto conjunto das relações e conflitos de poder, a partir de práticas e ações sociais concretas e conscientes. 
Fundamental é sublinhar que o artigo 5ㅇ da Constituição da República Federativa do Brasil estabelece que todos os cidadãos devem receber o mesmo tratamento e que a dignidade humana é um bem imensurável e protegido pelo Estado e garantido pela sociedade. O artigo 196 legisla que a saúde é direito fundamental de todos e um dever do Estado, e deve ser garantido mediante políticas sociais e econômicas como acesso universal e igualitário às ações e serviços voltados para a promoção, a proteção, a recuperação e a reabilitação da saúde da população (BRASIL, 1998).

Isto posto, é válido trazer à reflexão a expressiva importância de estar atento à diversidade cultural nos espaços de produção de cuidado. Em 2001, a Unesco adotou a Declaração Universal sobre a Diversidade Cultural, reconhecendo-a como uma herança da humanidade e inseparável do respeito à dignidade humana. A diversidade cultural só pode ascender ao reconhecer o diálogo e o respeito entre civilizações e culturas, transpondo questões relativas a sexo, idade, nacionalidade, pertencimento cultural, religião ou etnia. É fonte de representações, conhecimentos, práticas e, igualmente, de afirmação, inovação e criatividade, que contribuem para a construção de um sistema relacional viável, sustentável e harmônico entre a humanidade e os recursos terrestres (BRASIL, 2012).

À Enfermagem e seus processo formativos sugere-se profundas reflexões, em especial no escopo da Teoria Transcultural, para que sua inserção nesses temas (re)emergentes da sociedade moderna recebam a ênfase necessária, a fim de que a humanização da assistência possa ultrapassar as fronteiras de uma mera política de saúde para uma ação de valorização, acolhimento e respeito ao usuário do serviço de saúde. Assim, serão possíveis a reinvenção do cotidiano de seus processos de trabalho e a transformação dos trabalhadores em agentes ativos das mudanças no serviço de saúde. Da mesma forma, promover a união dos usuários e sua rede sociocultural e familiar nos processos de cuidado pode ser um grande desafio, mas é um movimento emancipador, de valorização da escuta de como ele quer ser cuidado, além de ser potência para que o usuário seja corresponsável pelo seu cuidado.

Isto posto, $\mathrm{O}$ estudo tem como objetivo propor uma reflexão sobre a interculturalidade e a formação da Enfermagem.

\section{METODOLOGIA}

Optou-se por utilizar a revisão narrativa como método. Os estudos que realizam revisões de literatura e de produções científicas têm várias denominações, tais como revisão integrativa, sistemática, bibliográfica, e, entre tantas outras, a revisão narrativa, que permite estabelecer relações com produções anteriores, identificando temáticas recorrentes, apontando para novas perspectivas, consolidando uma área de conhecimento e construindo orientações de práticas pedagógicas para a formação de profissionais (ROCHA, 1999; VOSGERAU; ROMANOWSKI, 2014).

A revisão narrativa possibilita a realização de análises e interpretações amplas, de modo a compreender o "estado da arte" do assunto, sob um ponto de vista teórico ou contextual (ELIAS et al., 2012), com possibilidade de contribuir com a teoria e com a prática de uma área do conhecimento (MESSINA,1998). Nesta metodologia descreve-se 
o "estado da arte" sem utilizar critérios sistemáticos para a busca e análise crítica da literatura e a seleção dos estudos, e a interpretação das informações pode estar sujeita à subjetividade dos autores (USP, 2015).

Assim, embora não sistematizada, a revisão foi pautada na busca de artigos em periódicos, em especial os disponíveis nas bases de dados da Biblioteca Virtual de Saúde (BVS) do Ministério da Saúde e Centro Latino-Americano de Informação em Ciências da Saúde, Organização Pan-Americana de Saúde e Organização Mundial de Saúde. Para fundamentar a temática e complementar o estudo foram, ainda, realizadas pesquisas em legislações brasileiras transversais ao assunto e na base de dados Google acadêmico. A busca pelos artigos foi feita no segundo semestre de 2018.

\section{A INTERCULTURALIDADE NA ENFERMAGEM}

O debate sobre a interculturalidade na Enfermagem demanda um processo de reflexões que perpassam pela própria identidade da profissão. Observa-se, empiricamente, que ao longo dos anos a divisão de classes, a hegemonia de algumas profissões sobre a enfermagem e a própria história da sua caminhada têm sido pautas de um movimento emergente pelo desejo de ser ouvida como uma profissão com identidade própria e um campo crescente de conhecimento, de espaços de trabalho e de reconhecimento pelo usuário do serviço de saúde

A prática profissional da Enfermagem está alicerçada em muitas teorias, as quais conferem cientificidade às ações do enfermeiro e contribuem para a construção de um campo de conhecimento específico. São instrumentos que guiam a prática e se aplicam em todas as áreas de atuação da Enfermagem, tais como assistência, gerência, pesquisa e ensino. Entre essas, há a Teoria da Diversidade e Universalidade do Cuidado Cultural (TDUCC), proposta por Madeleine Leininger, enfermeira e antropóloga, a qual impulsionou a compreensão da importância social e da influência cultural sobre as crenças de saúde e os comportamentos dos indivíduos (COUTINHO et al., 2017), na década de 60 do século 20 .

De acordo com a teorista Madeleine Leininger, a enfermagem é essencialmente uma profissão de cuidados transculturais e interculturais, que assume a centralidade do cuidado na promoção do cuidado para pessoas, de uma maneira significativa e congruente, respeitando os valores culturais e os estilos de vida Estamos a falar de uma visão, à época, vanguardista, em que o enfermeiro passa a reconhecer o indivíduo como um ser cultural; detentor de uma forma muito particular de ver o mundo, em função das suas crenças, valores, costumes e práticas culturais, em detrimento de situar o seu interesse apenas nos problemas e ou necessidades biofisiológicas afetadas (COUTINHO et al., 2017, p. 1.579).

Esta teoria considera que a "visão de mundo dos indivíduos e as estruturas sociais e culturais influenciam seu estado de saúde, bem-estar ou doença". Ao enfermeiro cabe conhecer a situação cultural e possíveis determinantes do processo saúde e doença para serem usadas como ferramentas para o adequado planejamento e tomadas de decisão nos cuidados de Enfermagem. Por meio desta Teoria é possível entender e sensibilizar-se para a importância da preservação da identidade cultural do usuário de seus cuidados, minimizando-se a imposição cultural. Além disso, essa Teoria permite ao pro- 
fissional de Enfermagem conhecer a si mesmo, "evitando, assim, posições etnocêntricas que o possam libertar de preconceitos edificados na cultura subjetiva e naqueles que a sociedade lhe possa impor" (COUTINHO et al., 2017, p. 1.579).

Conforme Andrews e Boyle (2005), a Teoria da Enfermagem Transcultural propõe um instrumento de autoavaliação a fim de antecipar as dificuldades/facilidades do enfermeiro em cuidar de 30 diferentes tipos de indivíduos e agrupados em 5 categorias: étnicos/raciais (americano nativo, negro americano, mexicano americano, anglo-saxão branco, vietnamita americano, haitiano); assuntos/problemas sociais (abusadores de criança, prostitutas, gays/lésbicas, alcoólatras, usuários de drogas, adolescente grávida solteira); prejuízos físicos/mentais (pessoa senil ou anciã, ou com paralisia cerebral, amputados, com câncer, portadora de Aids, hemofílica); religiosos (judeus, protestantes, católicos, testemunhas de Jeová, Hare Krishna e ateus) e políticos (membro da Ku Klux Klan, neonazistas, proponentes de armamento nuclear, comunistas, sindicalistas, proponentes de união de pessoas do mesmo sexo).

Ao enfermeiro é solicitado estar habilitado para garantir um cuidado cultural competente. Para tanto, Pagliuca e Maia (2012) referem que ele necessita se autoavaliar e ajuizar se está apto a assumir a relação de cuidador com o ser cuidado em diferentes contextos e cenários. A autoavaliação deve considerar conflitos étnicos e raciais; problemas sociais e religiosos; dificuldades físicas e mentais e políticas inclusivas. Ao propor a autoavaliação das atitudes e valores dos enfermeiros diante das variações bioculturais dos usuários cuidados e grupos sociais, a Teoria da Enfermagem Transcultural pressupõe prover um processo de comunicação adequado.

Há três elementos envolvidos no processo de autoavaliação do enfermeiro para tal: a atitude, a habilidade instrumental e o compromisso social. "Quando avalia se está preparado para cumprimentar e aceitar o paciente, demonstra competências de atitude. Quando responde se está apto para ajudar e se conhece a situação biocultural do paciente, evidencia competências para o cuidado instrumental de enfermagem. Advogar ou defender o paciente confirma envolvimento social" (PAGLIUCA; MAIA, 2012, p. 852).

Diante destas considerações, percebe-se a importância da atenção, por parte das instituições formadoras, de compor, nos componentes curriculares, a transversalização do conhecimento e práticas interculturais tanto à formação técnica de Enfermagem quanto à Graduação e a Pós-Graduação. Os estudos apontam dificuldades no cuidado quando em interface com a diversidade cultural (BOTELHO; SECCHI, 2014; LIMA et al., 2016; ANDRADE; TERRA, 2018). A origem das doenças e os problemas da população migrante, por exemplo, estão implicados com o desconhecimento dos seus direitos, às dificuldades administrativas, de acesso aos serviços, dos custos dos tratamentos, à discriminação, à exclusão, à falta de suporte social, à precariedade das condições econômicas, habitacionais e de trabalho, a hábitos e crenças culturais e às barreiras linguísticas e comunicacionais, entre outros. Considera-se, ainda, os outros fatores determinantes do processo saúde/ doença, tais como os estilos de vida, a pobreza, o desemprego, o isolamento, a falta de informação e a baixa escolaridade (RAMOS, 2012). 
Relativamente aos cuidados de saúde aos índios, um estudo apontou que entre as maiores dificuldades dos profissionais de saúde no cuidado de Enfermagem a essa população está a falta de preparo destes trabalhadores para lidar com a cultura e costumes indígenas. $\mathrm{O}$ estudo assinalou que apesar de existirem políticas públicas que contemplem a assistência aos índios e ações preventivas a doenças, muitas vezes sua execução falha em virtude das dificuldades de comunicação dos profissionais da área na saúde com essas comunidades. Por exemplo, a pesquisa demonstrou que as consultas de Enfermagem ocorrem frequentemente com a presença de um agente indígena para que a comunicação seja facilitada, visto que a maioria dos enfermeiros não é indígena (ANDRADE; TERRA, 2018).

Além das barreiras de comunicação, a pesquisa revelou outras fragilidades relativas ao cuidado de Enfermagem, tais como desvalorização e/ou desconhecimento das práticas indígenas. Como exemplo, o cuidado e o processo de morte e do morrer das crianças indígenas, em geral, mobilizam muito mais os profissionais de saúde do que a própria comunidade; as práticas de educação em saúde desenvolvem-se de forma prescritiva, contrapondo-se à proposta de educação emancipatória, de construção de autonomia dos sujeitos nesse processo. A proposta contemporânea de educação em saúde envolve a fusão dos saberes científicos com os populares, sem a sobreposição de um e outro, daí a importância do conhecimento da especificidade cultural de cada etnia e a necessidade de saúde (ANDRADE; TERRA, 2018). Desconhecimento de práticas culturais e desvalorização das práticas de cuidado de índios e afrodescendentes também foram apontados em um estudo com enfermeiros, sobre seus saberes relativos a essas comunidades (LIMA et al., 2016).

Essa postura de desconsideração da cultura étnica fragiliza a produção do cuidado sob a perspectiva da integralidade, demonstrando o distanciamento desses profissionais quanto aos recursos complementares em saúde, aos pressupostos do Estatuto da Igualdade Racial e às recomendações da Política Nacional de Práticas Integrativas e Complementares, legisladas pelas Portarias no 971/2006 e no 1.600/2006, situação que favorece a não preservação de saberes nativos e a descaracterização étnica dos grupos, além de que, revela o predomínio do modelo biomédico, no qual o saber científico se sobrepõe ao saber próprio da cultura na qual o indivíduo está inserido. Ignorar ou desprezar saberes próprios dos usuários pode implicar dificuldades no diálogo entre profissional e usuários, o que favorece o insucesso terapêutico (LIMA et al., 2016).

Uma pesquisa que discutiu o tema saúde, tendo como referência um curso de Enfermagem em que participavam acadêmicos indígenas vinculados a um programa de inclusão indígena, demonstrou que, entre as razões que levaram estes estudantes a procurarem o referido curso destacaram-se "querer ajudar a sua comunidade [...], querer fazer o melhor pela comunidade" e, de forma muito expressiva, a constatação de que "enfermeiros de fora" que trabalhavam nas aldeias permaneciam por pouco tempo, em decorrência da falta de adaptação ao local, situação que deixava a comunidade desassistida por longos períodos. Também foi citada a constante falta de profissional, as dificuldades na assistência à saúde e as "longas distâncias a serem percorridas na procura de atendimento" (BOTELHO; SECCHI, 2014, p. 111). Os autores referem que a inter- 
culturalidade ainda é uma "via de mão única". Embora os indígenas sejam estimulados a exercerem a cidadania, o modelo educacional a que são submetidos desconsideram a alteridade e as trocas culturais, limitando-se, ainda, à imposição e não à inclusão.

A Enfermagem, em especial das unidades básicas de saúde, exerce grande influência no acolhimento e na assistência nos serviços prestados aos usuários, de um modo geral. Cuidados humanizados garantem vínculo com a população nos programas e ações para o atendimento de suas necessidades de saúde. Uma pesquisa mostrou que quase um terço da população de Lésbicas, Gays, Bissexuais, Travestis e Transexuais (LGBT) pesquisada já foi discriminada por profissionais de Enfermagem, situação relacionada à baixa procura pelos serviços de saúde. O compromisso do Sistema Único de Saúde (SUS) com a comunidade LGBT vem ampliando-se cada vez mais, principalmente inovando com políticas específicas sobre seus direitos a assistência à saúde, porém nesta pesquisa mais da metade desses usuários não tinha conhecimento dos seus diretos disponibilizados pelo SUS (BRAGA et al., 2018).

De acordo com um documento do Ministério da Saúde (MS), duas em cada três pessoas da população LGBT entrevistadas já haviam sofrido algum tipo de discriminação em decorrência da identidade sexual ou pelo gênero. O MS aponta que $14,5 \%$ dos participantes de um estudo, feito na Parada Gay de São Paulo, referiram já terem sofrido algum tipo de preconceito nos serviços de saúde. $O$ documento assinala que a discriminação, como no caso da homofobia, deve ser considerada fator impulsionador na produção de doença e sofrimento, e que agregada a outros determinantes, como desemprego, racismo, a inacessibilidade à moradia e à alimentação, agrava o quadro (BRASIL, 2008).

É válida uma recomendação descrita no Manual de Comunicação LGBT (aos profissionais da área da Comunicação), mas que pode ser atendido por todos os profissionais que se relacionam com essas pessoas, incluindo os trabalhadores da saúde, no cotidiano de suas práticas. Rotular segrega, exclui e inferioriza.

O uso de expressões como "moleques", "velhos", "lugar de mulher é na cozinha", "negro safado", "programa de índio", "ceguinho", "aleijadinho", "aidético", "homossexualismo", "opção sexual", "o travesti", "sapatão", "veado", "gilete", além de errado, pode ser ilegal e/ou prejudicar a honra e dignidade de milhões de pessoas e seus familiares. Ao substituir as expressões "moleques" por "crianças ou adolescentes", "lugar de mulher é na cozinha" por "mulheres têm o direito de ser independentes", "negro safado" por "negro que dá orgulho ao Brasil", "programa de índio" por "índios que povoavam o Brasil antes de nós", "ceguinho" por "deficiente visual", "aleijadinho" por "portador de deficiência física", "aidético" por "portador do vírus da Aids", "homossexualismo" por "homossexualidade", "opção sexual" por "orientação sexual", "o travesti" por "a travesti", "sapatão" por "lésbica", "veado" por "gay", "gilete" por "bissexual", entre outros termos, os profissionais de comunicação estão colocando sua responsabilidade social e seu profissionalismo acima dos preconceitos sociais (ABGLT, 2019, p. 7).

É requerido que profissionais de saúde estejam "atentos à reação em cadeia que implica o processo de vulnerabilidade que leva ao adoecimento dessa população, bem como às políticas públicas que facilitam o acesso ao sistema de saúde" (CARDOSO; FERRO, 2012, p. 562), situação que reforça a importância da formação dos trabalhadores da área da saúde para a diversidade. 
Insere-se nessa discussão uma citação de Campos e Andrade (2009, p. 5) quanto às questões do masculino e feminino. Homens e mulheres, construídos historicamente, com papéis sociais e sexuais previamente delimitados e com profissões e comportamentos adequados e permitidos para cada sexo, chegam à escola. "A escola recebe mulheres e homens que vivem no cotidiano das relações de desigualdade entre os gêneros. A problemática, então, consiste no que fará a escola: confirmará tais estereótipos ou tentará desconstruí-los?" Diante deste questionamento urge uma posição da escola, da universidade, da educação formal, informal e não formal sobre o assunto.

A diferenciação entre sexo e gênero ainda é desafiadora para as instituições educacionais e professores(as). É preciso diferenciar o sexo do gênero. Da mesma forma, as questões de sexo e gênero conduzem, quase sempre, ao tema da orientação sexual, conceitos e entendimentos também malcompreendidos ou desconhecidos pela sociedade brasileira. Assim, parece evidente que "a escola se sinta responsável em reprimir orientações sexuais que considere desviantes da norma socialmente estabelecida, devido a sua concepção de gênero natural, ou seja, muito relacionada aos aspectos biológicos" (CAMPOS; ANDRADE, 2009, p. 6).

Vale reforçar que gênero significa que homens e mulheres são produtos da realidade social e não decorrência da anatomia de seus corpos. Conceito criado para distinguir a dimensão biológica da dimensão social. Identidade de gênero é a percepção que uma pessoa tem de si como sendo do gênero masculino, feminino ou de alguma combinação dos dois, independente de sexo biológico. O sexo é biológico, um conjunto de informações cromossômicas, órgãos genitais, capacidades reprodutivas e características fisiológicas secundárias que distinguem machos e fêmeas (ABGLT, 2019).

$\mathrm{Na}$ abordagem de temas que envolvem raça/etnia e saúde, é preciso tecer algumas considerações acerca das assimetrias econômicas, de exclusão e de vulnerabilidades que aumentam as desigualdades. Relações de gênero desiguais reproduzem os estereótipos no nosso cotidiano, que interferem no desenvolvimento pleno de mulheres e de homens, além de exercerem significativa influência sobre outras desigualdades e/ou discriminação de classe, raça, religião, idade, orientação sexual, deficiência, etc. (LIMA, 2011).

Estas desigualdades estão apresentadas em documentos do Instituto de Pesquisa Econômica Aplicada (IPEA, 2015) e do Instituto Brasileiro de Geografia e Estatística (IBGE, 2017), nos quais consta que a taxa de analfabetismo entre as mulheres a partir de 15 anos é de 4,9\%, entre as brancas e 10,2\% entre negras. O IBGE identificou que, entre as adolescentes com idade entre 15 e 17 anos, o atraso escolar é de 30,7\% das pretas ou pardas e de $19,9 \%$ das mulheres brancas. Quanto ao ensino universitário, 23,5\% das mulheres brancas têm Ensino Superior completo e 10,4\% de mulheres pretas ou pardas têm o nível universitário completo.

Por razões sociais ou de discriminação, as mulheres negras têm menor acesso aos serviços de saúde de boa qualidade, à atenção ginecológica e à assistência obstétrica, seja no pré-natal, parto ou puerpério. As causas de morte materna estão relacionadas à predisposição biológica das negras para algumas doenças, como a hipertensão arterial, fatores relacionados à dificuldade de acesso, à baixa qualidade do atendimento recebido e à falta de ações e capacitação de profissionais de saúde voltadas para os ris- 
cos específicos aos quais as mulheres negras estão expostas. Há maior risco nas negras, comparadas às brancas, de contrair e de morrer mais cedo de determinadas doenças (BRASIL, 2005).

Entre as doenças que mais acometem a população negra brasileira estão as geneticamente determinadas, tais como doença falciforme, deficiência de glicose 6-fosfato, deficiência de glicose 6-fosfato desidrogenase, foliculite; as adquiridas devido às condições desfavoráveis, tais como desnutrição, anemia ferropriva, doenças do trabalho, DST/HIV/Aids, mortes violentas, mortalidade infantil elevada, abortos sépticos, sofrimento psíquico, estresse, depressão, tuberculose, transtornos mentais e as de evolução agravada ou tratamento dificultado, tais como hipertensão arterial, Diabetes Mellitus, coronariopatias, insuficiência renal crônica, câncer e miomatoses (BRASIL, 2010, p. 15).

A hipertensão arterial é mais frequente, inicia-se mais precocemente e apresenta uma evolução mais grave na população negra. As negras têm $50 \%$ a mais de chances de desenvolver diabetes que as brancas. Na população diabética, a hipertensão arterial é duas vezes maior nas negras do que na população geral. Mulheres negras portadoras de diabetes estão mais expostas à gravidez de alto risco (BRASIL, 2005).

Oportuno é ressaltar que as doenças ligadas à pobreza, como desnutrição, verminoses, gastroenterites, infecções, alcoolismo, violência (o racismo exerce influência sobre as diversas violências), são prevalentes na população negra e não devido a razões étnicas, dados que podem ser explicados pelas maiores dificuldades de acesso a serviços de saúde, meios diagnósticos e terapêuticos, conjuntura que pode produzir, em geral, evolução e prognóstico piores (LIMA, 2016).

Pode-se perceber a importância do tema ser refletido e discutido nos bancos escolares, reforçada pela Política Nacional de Saúde Integral da População Negra, que reconhece o racismo, as desigualdades étnico-raciais e o racismo institucional como determinantes sociais das condições de saúde, com vistas à promoção da equidade em saúde e legisla sobre a inclusão dos temas Racismo e Saúde da População Negra nos processos de formação e educação permanente dos trabalhadores da saúde e no exercício do controle social na saúde (BRASIL, 2009).

Não se pode negligenciar, nesta discussão, o "conceito ampliado" de saúde, ou seja, que a saúde é decorrente das condições de alimentação, habitação, educação, renda, meio ambiente, trabalho, transporte, emprego, lazer, liberdade, acesso e posse da terra e acesso aos serviços de saúde, resultante das formas de organização social e de produção (BRASIL, 1986). Diante desse conceito, depreende-se que alguns grupos da população são mais saudáveis e/ou mais vulneráveis que outros e que ocorrem desigualdades em consequência das condições sociais dos ambientes de vida e trabalho. Injustiças, desigualdades, parcialidades podem ser denominadas iniquidades e é sobre estas que devem se concentrar os esforços dos profissionais de saúde comprometidos com a igualdade e equidade de direitos, incluindo-se, nesta pauta, a interculturalidade e suas fragilidades. Prevenir agravos e promover a saúde de forma equitativa e/ou igualitária precisa ser prioridade, da formação ao exercício destes profissionais.

A promoção da saúde é uma das estratégias de produção de saúde que, articulada às demais estratégias e políticas do Sistema Único de Saúde, contribui para a criação de ações transversais que possibilitem atender às necessidades sociais em saúde. Sua po- 
lítica tem como objetivo geral promover a qualidade de vida e reduzir vulnerabilidades e riscos à saúde, relacionadas aos determinantes e condicionantes do processo saúde-doença. Suas diretrizes estão alicerçadas na integralidade, equidade, responsabilidade sanitária, participação social, intersetorialidade, informação, educação, comunicação e sustentabilidade (BRASIL, 2012), portanto com metas que englobam as populações vulneráveis, a diversidade, a interculturalidade.

Assim, emerge, cada vez mais, a necessidade de que sejam estabelecidos espaços nas universidades para uma discussão ampla sobre a sua função social, a fim de que seja possível considerar e praticar "alternativas educacionais emancipatórias e junto a tudo isso, proporcionar uma reflexão sobre o sistema escolar, o currículo, o material didático e a formação de professores". Os processos formativos necessitam estar focados nesta problemática, visto que a educação intercultural é uma proposta político-pedagógica que vislumbra a formação para a cidadania e a superação de preconceitos e discriminações que expropriam de seus direitos os indivíduos e as comunidades (VIEIRA, 2001).

\section{QUEM ENSINA? COMO ENSINA? SOB QUE FUNDAMENTOS ENSINA ENFERMAGEM E INTERCULTURALIDADE?}

Toda a educação precisa basear-se numa boa disposição, tolerância e reciprocidade em relação ao outro. Tanto os professores como as políticas educacionais, em âmbito municipal, estadual e nacional são fundamentais para que esse processo de mudança e abertura aconteça (ROMANI; RAJOBAC, 2011). A interculturalidade na educação é uma proposta pedagógica que tem o intuito de desenvolver relações de cooperação, respeito e aceitação, entre diferentes culturas e sujeitos, visando, dessa forma, a preservar as identidades culturais, com a finalidade de propiciar a troca de experiências e o enriquecimento mútuo (ROMANI; RAJOBAC, 2011).

É recomendável que gestores e profissionais de saúde sejam formados sob essa perspectiva. Ao contrário, nos encontros com a diferença cultural, durante procedimentos de cuidado, podem ocorrer reações emocionais e comportamentos de rejeição e abandono, preconceito, discriminação e violência por parte dos profissionais de saúde, especialmente em ambientes nos quais não há preocupação em saber sobre a cultura do usuário do serviço, nem pessoal com formação na área da comunicação e das relações interculturais. Dificuldades de comunicação, em especial interculturais, podem fragilizar o trabalho dos profissionais de saúde, favorecendo erros de diagnóstico e falhas na adesão às orientações desses profissionais (RAMOS, 2012).

A comunicação é fundamental nos processos de cuidado e de educação em saúde. No domínio da saúde sua importância duplica e precisa abraçar a formação, a pesquisa e a intervenção, numa perspectiva sistêmica, interativa e multi/interdisciplinar. 0 encontro interdisciplinar entre saúde, comunicação e cultura envolve novos paradigmas e desafios estratégicos, políticos, teóricos e metodológicos nas áreas de prevenção, informação, educação e promoção da saúde, bem como das competências comunicacionais e interculturais, cada vez mais presentes no campo da saúde.

Para refletir sobre a pluralidade cultural e inclusão é preciso mais do que "[...] retóricas sobre a diversidade [...] palavras suaves, de eufemismos que tranquilizam nossas consciências ou produzem a ilusão de que assistimos a profundas transformações so- 
ciais e culturais simplesmente porque elas se resguardam em palavras de moda" (DUSCHATZKY; SKLIAR, 2000, p. 163). Nesta conjuntura, Ramos (2007, p. 235) entende que "o professor tem de promover um ensino dialógico em que as diferenças, a alteridade e a diversidade sejam contempladas, em que o diálogo entre as culturas seja promovido e em que os preconceitos e os estereótipos sejam eliminados". Cabe aos educadores, professores e intelectuais progressistas contribuir, do ponto de vista teórico e prático, para uma educação superior emancipatória, popular e intercultural e romper com um certo imperialismo acadêmico "colonizante, monocultural, ainda dominante", e que constituiu o grande pressuposto da formação das universidades (TAVARES, 2013, p. 71)

E, para a mudança das práticas docentes é solicitado conhecer, divulgar, investigar e socializar novas formas de educar e aprender saúde e, sobretudo, a mobilização de educadores, profissionais e gestores para parcerias colaborativas, na busca da promoção da saúde (FONTANA, 2018). É preciso ênfase no enfoque étnico-racial nos estudos que envolvem a saúde, como forma de reconhecimento da discriminação histórica sofrida pela população negra (NASCIMENTO, 2018).

As novas competências dos profissionais de enfermagem, assim como o desenvolvimento de técnicas médicas e científicas, a livre circulação dos profissionais de enfermagem, a diversidade cultural e social dos dias atuais, podem determinar as necessidades e exigências mais concretas e, ao mesmo tempo, uma formação mais ampla. [...] A realidade da formação acadêmica do profissional de enfermagem mudou radicalmente nas últimas décadas, pois para manter o ritmo da prática clínica atual frente a tradicional, os "novos" profissionais de enfermagem devem ter mais conhecimentos sobre determinadas áreas de trabalho, atendendo uma demanda social e de saúde da população (ORTEGA et al., 2015, p. 408-409).

$\mathrm{Na}$ área da Enfermagem é recomendável ao professor apreender que a situação contemporânea da saúde exige um professor orientador das práticas do exercício profissional em diálogo ou conectado com o que exige a realidade no seu tempo histórico e cultural. As Diretrizes Curriculares Nacionais (DCNs) para os cursos da área de Enfermagem legislam sobre o perfil do profissional enfermeiro e destacam a necessidade social da formação profissional ser generalista, humanista, crítica e reflexiva, qualificado ao exercício da Enfermagem, com base no rigor científico e intelectual, pautado em princípios éticos (BRASIL, 2001). Embora as DCNs já tenham sido amplamente discutidas desde $o$ ano de 2001, percebe-se que o ensino na Enfermagem ainda carece de atividades que fortaleçam práticas pedagógicas diferenciadas. Observam-se dificuldades sob o aspecto da descentralização do professor, principalmente aquelas que situem o estudante como sujeito ativo e central do processo de ensino (OLIVEIRA et al., 2015). Em que medida essa reflexão se conecta com a interculturalidade na formação? Na medida em que considera o estudante na perspectiva de sujeito, posição que se constitui como uma forma de garantir a possibilidade da interculturalidade.

De acordo com Philippe Perrenoud, são competências a serem desenvolvidas pelo (a)professor(a) para sua prática: organizar e dirigir situações de aprendizagem; administrar a progressão das aprendizagens; conceber e fazer evoluir os dispositivos de diferenciação; envolver os alunos em suas aprendizagens e em seu trabalho; trabalhar em equipe; participar da administração institucional; informar e envolver a rede de apoio; 
utilizar novas tecnologias; enfrentar os deveres e os dilemas éticos da profissão; administrar a própria formação contínua (OLIVEIRA et al., 2015). É possível que muitos professores necessitem de atualização de seus saberes para os novos tempos da sociedade globalizada, inclusiva, intercultural.

A situação que se configura no cenário da saúde exige a vivência de espaços que possibilitem a troca de saberes e de experiências na busca de soluções para os nós críticos das comunidades cuidadas. É preciso que se oportunize o fortalecimento dos saberes de cada um, que se respeite a subjetividade e diversidade de quem participa do processo de cuidar. Os processos formativos de educação em saúde para a interculturalidade carecem de uma prática problematizadora que oportunize o diálogo entre os participantes, a autonomia cidadã e contribua para a promoção da adoção de posturas ativas em seus ambientes políticos e sociais, em sintonia com as ideias de Paulo Freire, cujos pressupostos implicam a concepção de que educar não significa a mera transferência de saber, mas um encontro de sujeitos interlocutores na busca de (re)significação dos significados e a articulação entre educação e saúde no escopo da relação interpessoal, cuidado e respeito e se configura como uma das mais ricas fontes de interdisciplinaridade e de interculturalidade em saúde coletiva (FONTANA; SANTOS; BRUM, 2013).

Inserir o professor nos debates interculturais é tão ou mais importante do que sensibilizar estudantes, visto que envolve a transformação de suas práticas metodológicas com vistas a transformar conceitos do aprendiz. Assim, a atenção do professor deve voltar-se, inicialmente para seus conceitos sobre o tema, para, diante do autoconhecimento reflexivo, empoderar-se das especificidades da educação intercultural e da pesquisa na área. $E$, inicialmente, sensibilizar-se para a "diversidade cultural e para 0 desafio a estereótipos e preconceitos relacionados a gênero, raça, classe social, padrões culturais" (CANEN, 1999, p. 90). A partir disso, investimentos na formação dos professores podem agregar valor à docência contemporânea, de característica inclusiva, ética e emancipatória.

A formação continuada de professores se justifica neste contexto, visto que os prepara para refletirem e trabalharem com a diversidade cultural no contexto educacional e abre espaços para a transformação da escola em um local em que as diferentes identidades são respeitadas e valorizadas, atuando em favor da cidadania. Significa refletir sobre mudança de atitude, de postura e de olhar sobre a diversidade e a diferença e,

não mais a celebração acrítica da diversidade, e sim o questionamento, a participação e a decodificação de teorias, conceitos, discursos e mensagens que compõem o currículo e as práticas em sala de aula e que muitas vezes se apresentam impregnados de preconceitos, estereótipos, silêncios e omissões. Para tanto, o diálogo apresenta-se como um instrumento indispensável, a partir do qual professores e alunos possam estabelecer uma dinâmica de entendimento e reflexão, em que as "vozes" de todos sejam ouvidas, consideradas e debatidas (CANEN; XAVIER, 2011, p. 643).

Pensar a formação de professores sob o prisma da interculturalidade ainda tem um longo caminho a percorrer. As escassas produções científicas apontam, especialmente, para as necessidades existentes nesse campo, entretanto ainda se desconhece como se dão as práticas no interior do cotidiano escolar. Ainda existem dificuldades em 
encontrar orientadores para a pesquisa na área; há um significativo, porém ainda pequeno, número de intelectuais negros nas instituições de ensino superior, em centros de pesquisa, etc. Ainda são frágeis as preocupações com a "formação de formadores, ou seja, como preparar os educadores do ensino superior, que formam os educadores da educação fundamental para que possam aportar qualificada discussão sobre a questão da diferença e da diversidade, a partir de uma perspectiva crítica". Ainda se discute com os acadêmicos, sob "lençóis teóricos", "bordados" com "saberes científicos oficiais". A produção acadêmica ainda está distanciada da realidade escolar (SILVA, 2013, p. 5), problemática que pode ser extensiva à formação técnica e de graduação de enfermagem.

Nesta perspectiva o autor (SILVA, 2013) sugere a pesquisa-ação, colaborativa, cooperativa e/ou crítica como principais metodologias para que se produza conhecimento à formação de professores para a interculturalidade. Descreve ele a potencialidade da pesquisa-ação como um recurso privilegiado no tratamento da diversidade cultural em espaços educativos e para conhecer em profundidade o cotidiano do trabalho docente. A observação etnográfica, as entrevistas orais, o uso imagético (fotografia e vídeo), combinadas com estratégias de cunho quantitativo podem agregar valor à pesquisa. Assim, pode-se inferir que a pesquisa pode servir de alicerce para a transformação das práticas docentes quanto à interculturalidade focada na minimização das diferenças sociais.

Para Canen e Xavier (2011), novas produções acadêmicas podem adicionar-se às existentes nessa perspectiva, para se dispor de mais narrativas, a partir das vozes dos professores-pesquisadores e seus desdobramentos curriculares e culturais no contexto das práticas docentes. A associação da formação continuada de professores com as perspectivas culturais carece ser mais bem exploradas, a fim de que possa proporcionar, a pesquisadores e professores, reflexões que caminhem para a conquista de uma escola mais justa e democrática, articulada com a realidade sociocultural plural brasileira.

Por fim, vale ressaltar que, a Política de Humanização da Assistência (BRASIL, 2003) vai ao encontro de toda a problemática das dificuldades na atenção à saúde diante da diversidade cultural. Assim, é preciso reconhecer de fato os princípios da referida política e alicerçar os construtos da formação em Enfermagem sobre ela.

A referida Política tem, entre suas diretrizes, o acolhimento. Acolher é reconhecer o que o outro traz como legítima e singular necessidade de saúde. É salutar o acoIhimento sustentar a relação entre equipes/serviços e usuários/populações. Com uma escuta qualificada oferecida pelos profissionais às necessidades do usuário, é possível garantir o acesso oportuno desses usuários a tecnologias adequadas às suas necessidades, ampliando a efetividade das práticas de saúde. Isso assegura, por exemplo, que todos sejam atendidos com prioridades a partir da avaliação de vulnerabilidade, gravidade e risco. Entre outras premissas, aposta na defesa de um SUS que reconhece a diversidade do povo brasileiro e a todos oferece a mesma atenção à saúde, sem distinção de idade, etnia, origem, gênero e orientação sexual.

\section{CONSIDERAÇÕES FINAIS}

Diante das reflexões produzidas pode-se inferir, fortemente, que as instituições formadoras responsáveis por cursos da área da saúde, como a Enfermagem, escopo deste artigo, devem construir seus componentes curriculares com espaços para a in- 
terculturalidade. A Enfermagem, como área que mais tempo permanece com o usuário do serviço de saúde, apropriando-se desses saberes, pode desenvolver seus cuidados de forma humanizada e comprometida com os princípios do Sistema Único de Saúde, o qual garante acesso integral e universal para toda a população do país ao sistema público de saúde, sem discriminação.

A interculturalidade tangenciando componentes curriculares dos cursos da saúde, tem a potência de minimizar preconceitos e desenvolver a alteridade, a valorização e o conhecimento da cultura do outro, tão intensamente necessária para a sua sobrevivência enquanto ser no mundo. Adequar a rotina do cuidado de modo a atender às demandas culturais, predispondo-se a aprender sempre com a diversidade cultural, de gênero, étnica, sexual, biológica, religiosa, linguística, etc., atendendo às solicitações do que é diferente, plural, como um fenômeno social de relação estreita com a globalização e as sociedades pós-modernas, agrega valor ao cuidado.

Ademais, sugere-se investir na pesquisa científica sobre o tema. Ainda são escassas as produções científicas que abordam as disparidades sociais como fator determinante de adoecimento. É preciso fomentar a pesquisa e a educação na área da saúde para além do hegemônico, do ensino e do cuidado meramente prescritivo, de modo a desenvolver nos estudantes a sua cidadania como meio para respeitar a cidadania do outro, no alcance de uma sociedade mais justa, solidária e ética.

\section{REFERÊNCIAS}

ANDRADE, G. A. S. C. R.; TERRA, M. F. Assistência de enfermagem à população indígena: um estudo bibliográfico. Arq Med Hosp Fac Cienc Med Santa Casa, São Paulo, v. 63, n. 2, p. 100-104, 2018.

ANDREWS, M. M.; BOYLE, J. S. Transcultural concepts in nursing care. 5. ed. Philadelphia: Lippincott Williams \&Wilkins, 2005.

ABGLT. Associação Brasileira de Lésbicas, Gays, Bissexuais, Travestis e Transexuais. Manual de Comunicação Lésbicas, Gays, Bissexuais, Travestis e Transexuais (LGBT). Disponível em: http://www.observatoriodegenero.gov.br/menu/noticias/manual-de-comunicacao-lgbt.pdf/view. Acesso em: 9 jan. 2019.

BOTELHO, M. T. S. L.; SECCHI, D. A formação superior do enfermeiro indígena: desafios da interculturalidade. Revista Fórum Identidades, Itabaiana: GEPIADDE, v. 16, ano 8, 2014.

BRAGA, L. S. et al. Inovação da assistência à saúde prestada à população lésbica, bissexuais, gays, travestis e transexuais. Revista Brasileira de Ciências da Vida, [S.I.], v. 6, n. Especial, abr. 2018. ISSN 2525-359X. Disponível em: http://jornal.faculdadecienciasdavida.com.br/index.php/RBCV/article/view/765. Acesso em: 3 jan. 2019.

BRASIL. Constituição da República Federativa do Brasil. Brasília, DF: Senado Federal, 1988. Disponível em: http://www.planalto.gov.br/ccivil_03/Constituicao/Constituicao.htm. Acesso em: 2 dez. 2018.

BRASIL. Política Nacional de Humanização, 2003. Disponível em: http://portalms.saude.gov.br/acoes-e-programas/politica-nacional-de-saude-bucal/legislacao/693-acoes-e-programas/40038-humanizasus. Acesso em: 3 dez. 2018.

BRASIL. Ministério da Saúde. Perspectiva da equidade no pacto nacional pela redução da mortalidade materna e neonatal: atenção à saúde das mulheres negras. Brasília: Ministério da Saúde, 2005. 20p. Disponível em: http://bvsms.saude.gov.br/bvs/publicacoes/perspectiva_equidade_pacto_nacional.pdf. Acesso em: 20 dez. 2018.

BRASIL. Ministério da Saúde. Comissão Nacional dos Determinantes Sociais da Saúde - CNDSS. Determinantes sociais da saúde ou por que alguns grupos da população são mais saudáveis que outros? Rio de Janeiro: Fiocruz, 2006.

BRASIL. Ministério da Saúde. Saúde da população de gays, lésbicas, bissexuais, travestis e transexuais. Rev. Saúde Pública, 42(3), p. 570-573, 2008. 
BRASIL. Ministério da Saúde. Portaria no 992, de 13 de maio de 2009. Institui a Política Nacional de Saúde Integral da População Negra. Disponível em: http://bvsms.saude.gov.br/bvs/publicacoes/politica_nacional_saude_populacao_negra_3d.pdf. Acesso em: 7 dez. 2018.

BRASIL. Ministério da Saúde. Secretaria-Executiva. Secretaria de Vigilância em Saúde. Glossário temático. Brasília: Ministério da Saúde, 2012. Disponível em: http://bvsms.saude.gov.br/bvs/publicacoes/glossario_tematico_promocao_saude.pdf. Acesso em: 20 out. 2018.

BRASIL. Fundação Oswaldo Cruz (Fiocruz). Humanização, 2018. Disponível em: https://pensesus.fiocruz. br/humanizacao. Acesso em: 12 dez. 2018.

BRASIL. Ministério da Saúde. Secretaria de Gestão Estratégica e Participativa. Departamento de Apoio à Gestão Participativa. Política Nacional de Saúde Integral da População Negra: uma política para o SUS. Brasília: Editora do Ministério da Saúde, 2010.

BRASIL. Ministério da Saúde. Oitava Conferência Nacional de Saúde. Relatório Final. Disponível em: http://bvsms.saude.gov.br/bvs/publicacoes/8_conferencia_nacional_saude_relatorio_final.pdf. Acesso em: 23 ago. 2019.

BRASIL. Conselho Nacional de Educação. Câmara de Educação Superior. Resolução CNE/CES N. 3, de 7 de novembro de 2001. Institui as Diretrizes Curriculares Nacionais do curso de Graduação em Enfermagem. Diário Oficial da República Federativa da União. Brasília, 9 nov. 2001. Seção 1, p. 37.

CAMPOS, P. N.; ANDRADE, M. A educação intercultural e a perspectiva de gênero. 2009. Disponível em: http://www.puc-rio.br/pibic/relatorio_resumo2009/relatorio/ctch/edu/patricia.pdf. Acesso em: 8 nov. 2018.

CANEN, A. Multiculturalismo e formação docente: experiências narradas. Educação e Realidade, Porto Alegre, RS, v. 24, n. 2, p. 89-102, 1999.

CANEN, A.; XAVIER, G. P. M. Formação continuada de professores para a diversidade cultural: ênfases, silêncios e perspectivas. Revista Brasileira de Educação (Impresso), v. 16, p. 641-662, 2011.

CANDAU, V. M. Direitos humanos, educação e interculturalidade: as tensões entre igualdade e diferença. In: Revista Brasileira de Educação, v. 13, n. 37, 2008.

CARDOSO, M. R; FERRO, L. F. Saúde e população LGBT: demandas e especificidades em questão. 21. ed. Universidade Federal do Paraná: [s.n.], 2012. 552p. v. 32. Disponível em: http://www.scielo.br/scielo. php?pid=S1414-98932012000300003tlng=pt. Acesso em: 20 dez. 2018.

COUTINHO, E. et al. O cuidado cultural na trajetória da enfermagem transcultural e competência cultural. CONGRESSO IBEROAMERICANO DE INVESTIGAÇÃO QUALITATIVA (CIAQ), 6., 2017. Atas [...]. v. 2, 2017. Disponível em: https://proceedings.ciaiq.org/index.php/ciaiq2017/article/view/1510. Acesso em: 11 dez. 2018.

DUSCHATZKY, Silvia; SKLIAR, Carlos. Os nomes dos outros: reflexões sobre os usos escolares da diversidade. Educação \& Realidade, Porto Alegre, v. 25, n. 2, p. 163-78, 2000.

ELIAS, C. S. et al. Quando chega o fim? Uma revisão narrativa sobre terminalidade do período escolar para alunos deficientes mentais. SMAD: Revista Electrónica en Salud Mental, Alcohol y Drogas, v. 8, n. 1, p. 4853, 2012.

FLEURI, R. M. Intercultura e educação. Revista Grifos, n. 15, p. 16-47, maio 2003.

FONTANA, R. T. O processo de educação em saúde para além do hegemônico na prática docente. Revista Contexto e Educação, Ijuí: Ed. Unijuí, ano 33, n. 106, p. 84-98, set./dez. 2018. Disponível em: http://dx. doi.org/10.21527/2179-1309.2018.106.84-98.

FONTANA, R.T.; SANTOS, A.V.; BRUM, Z. P. A educação em saúde como estratégia para a sexualidade saudável. J. Res.: Fundam. Care. On-line, v. 5, n. 4, p. 529-536, out./dez. 2013. Disponível em: http://bases. bireme.br/cgi-bin/wxislind.exe/iah/online/?IsisScript=iah/iah.xisexprSearch=24958indexSearch=ID. Acesso em: 20 nov. 2018.

HEPBURN, M. A. O multiculturalismo, as mídias e a educação. In: DELORS, J. (org.). A educação para o século XXI: questões e perspectivas. Trad. Fátima Murad. Porto Alegre: Artmed, 2005. p. 254-256.

HOLLANDA, A.; ROLLEMBERG, M. Diversidade cultural. In: BRASIL. Ministério da Cultura. Disponível em: http://www.cultura.gov.br/artigos/-/asset_publisher/WDHlazzLKg57/content/diversidade-cultural-523513/10883. Acesso em: 21 nov. 2018.

IPEA. Instituto de Pesquisa Econômica Aplicada. Retrato das desigualdades de gênero e raça - 1995-2015. Brasília: Ipea, 2015. Disponível em: http://www.ipea.gov.br/portal/images/stories/PDFs/170306_retrato_das_desigualdades_de_genero_raca.pdf. Acesso em: 20 jul. 2017. 
IBGE. Instituto Brasilieiro de Geografia e Estatística. População chega a 205,5 milhões, com menos brancos e mais pardos e pretos. Brasília, 24 nov. 2017. Última Atualização: 27 nov. 2017, 11h26. Disponível em: https://agenciadenoticias.ibge.gov.br/agencia-noticias/2012-agencia-denoticias/noticias/18282-pnad-c-moradores.html. Acesso em: 7 abr. 2018.

LEININGER, M. Transcultural nursing perspectives: basic concepts, Principles, and culture care incidents. In: LEININGER, M. Transcultural nursing: concepts, theories, research \& practices. 2. ed. 1998. p. 57-92I.

LIMA, M. R. A. et al. Atuação de enfermeiros sobre práticas de cuidados afrodescendentes e indígenas. Rev Bras Enferm, v. 69, n. p. 840-846, 844, set./out. 2016.

LIMA, M. G. Gênero, raça/etnia e saúde: interfaces dos saberes e práticas da enfermagem. Cuidado de enfermagem, ética e Inovação: 42a jornada Maranhense de Enfermagem e 72a edição da Semana Brasileira de Enfermagem, 2011. Disponível em: http://www.abennacional.org.br/secaoma/anaissben/mesa_redonda/02.pdf. Acesso em: 24 ago. 2019.

MESSINA, G. Estudio sobre el estado da arte de la investigación acerca de la formación docente en los noventa. Trabalho apresentado à Reunión de Consulta Técnica sobre investigación en Formación del Profesorado, Organización de Estados Ibero-Americanos para la Educación, la Ciência y la Cultura, México, 1998.

NASCIMENTO, S. S. Saúde da mulher negra brasileira: a necessária intersecção em raça, gênero e classe. Cadernos do CEAS, Salvador, Recife, n. 243, p. 91-103, jan./abr. 2018.

OLIVEIRA, S. N. et al. Professores de enfermagem e o desenvolvimento de competências: reflexões sobre a teoria de Philippe Perrenoud. Rev. Enferm. UFSM, v. 5, n. 3, p. 589-596, abr./jun. 2015.

ORTEGA, M. C. B. et al. Formação acadêmica do profissional de enfermagem e sua adequação às atividades de trabalho. Rev. Latino-Am. Enfermagem, v. 23, n. 3, p. 404-410, maio/jun. 2015. DOI: 10.1590/01041169.0432.2569.ordem alfab.

PAGLIUCA, L. M. F; MAIA, E. R. Competência para prestar cuidado de enfermagem transcultural à pessoa com deficiência: instrumento de auto avaliação. Rev Bras Enferm, Brasília, v. 65, n. 5, p. 849-855, set./out. 2012.

RAMOS, M. N. P. Comunicação em saúde e interculturalidade - perspectivas teóricas, metodológicas e práticas. RECIIS - R. Eletr. de Com. Inf. Inov. Saúde, Rio de Janeiro, v. 6, n. 4, dez. 2012 . Disponível em: https://www.reciis.icict.fiocruz.br/index.php/reciis/article/view/742. Acesso em: 10 dez. 2018.

RAMOS, N. Diversidade cultural, educação e comunicação intercultural. Políticas e estratégias de promoção do diálogo intercultural. Revista Educação em Questão, Natal: UFRN; CCSA, v. 34, n. 20, p. 9-32, 2009.

ROCHA, E. A. C. A pesquisa em Educação Infantil no Brasil: trajetória recente e perspectiva de consolidação de uma pedagogia da educação infantil. Florianópolis: UFSC - Centro de Ciências da Educação, Núcleo de Publicações, 1999.

ROMANI, S.; RAJOBAC, R. Por que debater sobre interculturalidade é importante para a Educação? Revista Espaço Acadêmico, n. 127, 2011.

SANCHEZ, F. S. La educación intercultural como criterio de calidad de las políticas educativas. In: LLORENTE, T. et al. (org.). Investigación Educativa: Diversidad y Escuela. Madri: Grupo Editorial Universitário, 2001. p. 135-166.

SILVA, G. F. Formação de professores e interculturalidade: uma revisão de literatura. Teoria e Prática da Educação, v. 16, n. 3, 2013.

TAVARES, M. A Universidade e a pluridiversidade epistemológica: a construção do conhecimento em função de outros paradigmas epistemológicos não-ocidentocêntricos, Revista Lusófona de Educação, v. 24, p. 49-74, 2013.

UNIVERSIDADE DE SÃO PAULO. Biblioteca Paulo de Carvalho Matos. Tipos de revisão da literatura. 2015. Disponível em: http://www.fca.unesp.br/Home/Biblioteca/tipos-de-evisao-de-literatura.pdf. Acesso em: 13 dez. 2017.

VIEIRA, R. S. Educação intercultural: uma proposta de ação no mundo multicultural. In: FLEURI, R. M. (org.). Intercultura: estudos emergentes. 1. ed. Ijuí: Ed. Unijuí, 2002. 150 p.

VOSGERAU, D. S. R.; ROMANOWSKI, J. P. Estudos de revisão: implicações conceituais e metodológicas. Rev. Diálogo Educ., Curitiba, v. 14, n. 41, p. 165-189, jan./abr. 2014.

WASH, C. La educación intercultural en la educación. Peru: Ministerio de Educación, 2001. Mimeografado. ZWIEREWICZ, M.; VALLEJO, A. P. Educação intercultural em entornos virtuais de aprendizagem. Revista Educação em Rede, v. 1. n. 1, 2006. 